\begin{tabular}{|c|c|}
\hline Title & $\begin{array}{l}\text { Jet-Precipitation Relation and Future Change of the Mei-Yu-Baiu Rainband and Subtropical Jet in CMIP5 Coupled } \\
\text { GCM Simulations }\end{array}$ \\
\hline Author(s) & Horinouchi, Takeshi; Matsumura, Shinji; Ose, Tomoaki; Takayabu, Y ukari N. \\
\hline Citation & $\begin{array}{l}\text { Journal of Climate, 32(8), 2247-2259 } \\
\text { https://doi.org/10.1175/JCLI-D-18-0426.1 }\end{array}$ \\
\hline Issue Date & 2019-04 \\
\hline Doc URL & http://hdl.handle.net/2115/75616 \\
\hline Rights & $\begin{array}{l}\text { (c) Copyright } 2019.4 .1 \text { A merican Meteorological Society (A MS). Permission to use figures, tables, and brief excerpts } \\
\text { from this work in scientific and educational works is hereby granted provided that the source is acknowledged. A ny use } \\
\text { of material in this work that is determined to be " fair use" under Section } 107 \text { of the U.S. Copyright Act or that } \\
\text { satisfies the conditions specified in Section } 108 \text { of the U.S. Copyright A ct (17 USC } \S 108 \text { ) does not require the } \\
\text { A MS' s permission. Republication, sy stematic reproduction, posting in electronic form, such as on a website or in a } \\
\text { searchable database, or other uses of this material, except as exempted by the above statement, requires written } \\
\text { permission or a license from the A MS. All A MS journals and monograph publications are registered with the Copyright } \\
\text { Clearance Center (http://www.copyright.com). Questions about permission to use material s for which A MS holds the } \\
\text { copyright can al so be directed to the AMS Permissions Officer at permissions@ ametsoc.org. A dditional details are } \\
\text { provided in the AMS Copyright Policy statement, available on the A MS website } \\
\text { (http://www.ametsoc.org/Copyrightl nformation). }\end{array}$ \\
\hline Tyре & article \\
\hline File Information & jcli-d-18-0426.1.pdf \\
\hline
\end{tabular}

Instructions for use 


\title{
Jet-Precipitation Relation and Future Change of the Mei-Yu-Baiu Rainband and Subtropical Jet in CMIP5 Coupled GCM Simulations
}

\author{
TAKESHI HORINOUCHI AND SHINJI MATSUMURA \\ Faculty of Environmental Earth Science, Hokkaido University, Sapporo, Hokkaido, Japan \\ TOMOAKI OSE \\ Meteorological Research Institute, Tsukuba, Ibaraki, Japan \\ YUKARI N. TAKAYABU \\ Atmosphere and Ocean Research Institute, The University of Tokyo, Kashiwa-shi, Chiba, Japan
}

(Manuscript received 2 July 2018, in final form 6 January 2019)

\begin{abstract}
Through extensive modeling efforts, it has been established that the ongoing global warming will increase the overall precipitation associated with the East Asian summer monsoon, but the future change of its spatial distribution has not reached a consensus. In this study, meridional shifts of the mei-yu-baiu rainband are studied in association with the subtropical jet by using outputs from atmosphere-ocean coupled climate models provided by CMIP5. The models reproduce observed associations between the jet and precipitation over wide time scales from synoptic to interannual. The same relation is found in intermodel differences in simulated climatology, so that the meridional locations of the jet and baiu precipitation are positively correlated. The multimodel-mean projection suggests that the both are shifted southward by the late twenty-first century. This shift is not inconsistent with the projected tropical expansion, not only because the change is local but also because the projected tropical expansion occurs mainly in the Southern Hemisphere. No significant future change in the continental mei-yu precipitation location is identified, which might be because the jet change is weak there. For comparison, the summertime Atlantic jet position, which shifts northward, is investigated briefly. This study suggests that the future change of the subtropical jet is an important aspect to investigate possible future changes of the baiu rainband, and it prompts further studies including the role of the ocean.
\end{abstract}

\section{Introduction}

The East Asian summer monsoon (EASM) affects the natural environment and human life in East Asia, so its plausible change in the ongoing global warming is of great interest. It has been pointed out that global warming increases global mean precipitation, and that the increasing trends should be greater where climatological precipitation is relatively larger (e.g., Chou and Neelin 2004; Held and Soden 2006). Many studies using coupled general circulation models (CGCMs) and atmospheric GCMs (AGCMs) have indicated that the

¿ Denotes content that is immediately available upon publication as open access.

Corresponding author: Takeshi Horinouchi, horinout@ees. hokudai.ac.jp precipitation associated with the EASM is expected to increase over the twenty-first century (e.g., Min et al. 2004; Kimoto 2005; Kitoh and Uchiyama 2006; Kripalani et al. 2007; Li et al. 2011; Kusunoki and Arakawa 2012).

However, there is not consensus as to how the distribution of the EASM precipitation will be changed. By using the June-August ERA-40 and ERA-Interim data, Li et al. (2010) showed that the EASM precipitation zone shifted southward during the period from 1958 to 2008 , but they did not find clear future change from their analysis of CGCM outputs based on the A1B scenario for the Fourth Assessment Report (AR4) coordinated by the Intergovernmental Panel on Climate Change (IPCC). Seo et al. (2013) analyzed CGCM outputs from the representative concentration pathway 6.0 (RCP6) experiments for phase 5 of the Coupled Model Intercomparison Project (CMIP5) for the June-August season (Taylor et al. 2012). They reported that the 
multimodel ensemble-mean results suggested little meridional shift of EASM precipitation from the late twentieth century to the late twenty-first century. Results from individual models may vary. For example, Yun et al. (2008) reported a southward shift from a model.

Summer subtropical rainbands are closely related to upper- to midtropospheric jets from synoptic to climatological time scales (e.g., Kodama 1992, 1993; Sampe and Xie 2010; Horinouchi 2014, hereinafter H14; Yokoyama et al. 2014; Yokoyama et al. 2017). Sampe and Xie (2010) suggested that warm advection by the jet in the midtroposphere induced upwelling favorable for precipitation. On the other hand, it is also pointed out that midtropospheric upwelling can be dynamically induced owing to the upper-level jet streaks (H14; Yokoyama et al. 2017). Synoptic aspects of the association of jet and precipitation are explained by H14. By exploiting quasigeostrophic dynamics, he revealed that upper-tropospheric-lower-stratospheric (UTLS) Rossby waves, which propagate through the waveguide associated with the climatological subtropical jet, modulate lower-tropospheric flows and induce secondary circulation to create precipitation belts several hundred kilometers to the south of the subtropical tropopause break. This break is characterized by potential vorticity contours of $\sim 2$ PVU (1 PVU $=10^{-6} \mathrm{~K} \mathrm{~kg}^{-1} \mathrm{~m}^{2} \mathrm{~s}^{-1}$ ) on the isentropic surfaces of $\sim 350 \mathrm{~K}$, which are often accompanied with an instantaneous jet axis. Horinouchi and Hayashi (2017, hereinafter HH17) further suggested the role of interaction between the upper-level jet and low-level jet to enhance precipitation. Its mechanism, the induction of secondary circulation by obliquely crossing upper and lower jets, can hold not only for the synoptic time scale but also for climatology. Therefore, it is of interest to analyze future projection by CGCMs on a wide range of time scales from synoptic to multidecadal to elucidate how jet-precipitation relations are reproduced in or differ among various GCMs and how the future climate projection can be interpreted in this perspective.

In this study, we focus on the mei-yu-baiu rainband, which is an important aspect of the EASM. Therefore, we focus on the early summer season, and we use data mostly for June and July. For reference, climatological precipitation based on satellite observation and zonal wind at $250-\mathrm{hPa}$ based on reanalysis is shown in Fig. 1.

To study possible future climate change, we use CGCM outputs collected in the CMIP5 database. Since the overall increase of the EASM precipitation is well established, we investigate other aspects; particular attention is paid to the future change of its meridional distribution.

Even though our goal is in the area of climatology and climate change, we begin with showing results from analysis of daily outputs from CGCMs. This is because we

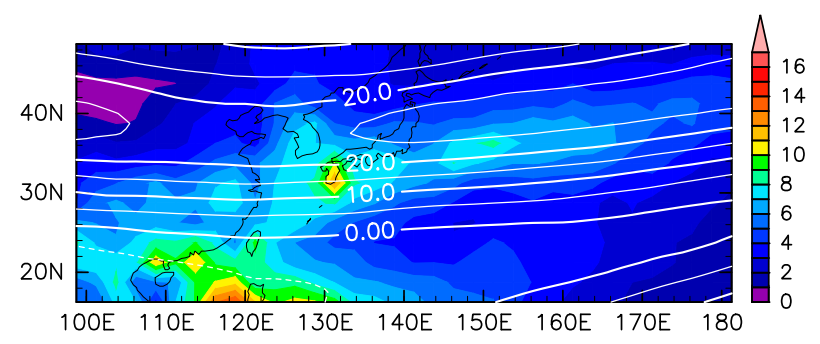

FIG. 1. Long-term mean precipitation over June and July during 1981-2010 from the CMAP standard product (color shading; $\mathrm{mm} \mathrm{day}^{-1}$ ) and 250 -hPa zonal wind over the same period from the JRA-55 (white contours; interval: $5 \mathrm{~m} \mathrm{~s}^{-1}$ ).

believe that it will help us understand the relationship between the subtropical jet and precipitation. Their relationship is investigated in a consistent manner over synoptic, monthly (intraseasonal and interannual), and multidecadal (climatological) time scales. The investigation includes whether and how well the observational relationship between the jet and precipitation is reproduced in CGCMs.

A number of factors can affect the climatological latitude of the subtropical jet axis. Influences of the SST front associated with Kuroshio and Oyashio Extensions on the atmospheric circulation and jet have been shown in preceding studies (e.g., Frankignoul et al. 2011; Nakamura and Miyama 2014; Matsumura et al. 2016; Matsumura and Horinouchi 2016). Tropical SST can also have an impact (e.g., Inatsu et al. 2002; Shaw and Voigt 2015).

The rest of this paper is organized as follows. The data and methods used are described in section 2. The relationship between the jet and precipitation at multiple time scales is explored in section 3. Future change in the climatological distributions in the mei-yu-baiu rainband is investigated in section 4 , where it is shown that the jet provides an important guidance for precipitation. The relationship between the jet and SST is briefly touched on in sections 3 and 4. A discussion is presented in section 5 in a wider perspective to cover the Atlantic and further to put the results in the context of the Hadley circulation in the zonal mean. Conclusions are drawn in section 6.

\section{Model, data, and method}

We used CGCM outputs in the CMIP5 database provided by Program for Climate Model Diagnosis and Intercomparison (PCMDI). The modeling categories used are the historical runs and the representative concentration pathways 4.5 and 8.5 (RCP4.5 and RCP8.5). To focus on the mei-yu-baiu period, we used data for June and July over the years 1979-99 (historical runs) and 2079-99 (RCP runs). Monthly mean data are taken from 32 models [ACCESS1.0, ACCESS1.3, BCC-CSM1.1, BCC-CSM1.1-M, CanESM2, CCSM4, CESM1(BGC), CESM1-CAM5, 


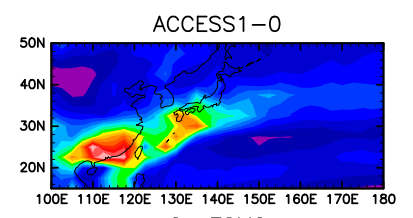

CanESM2
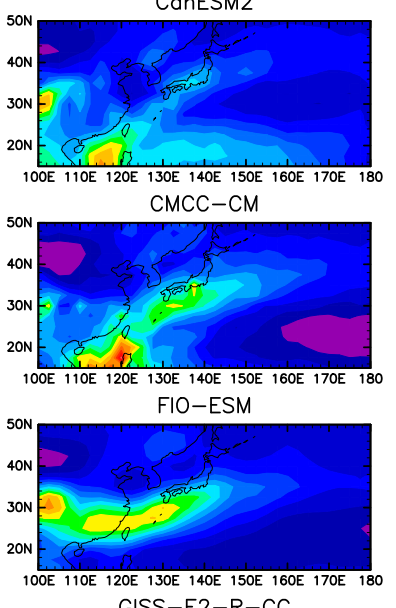

GISS-E2-R-CC
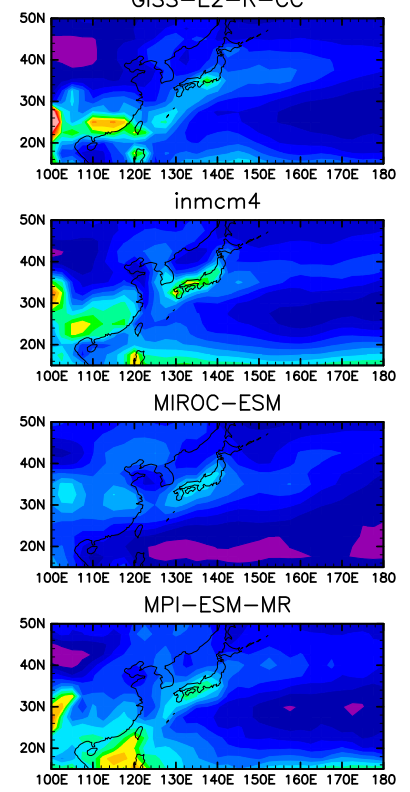

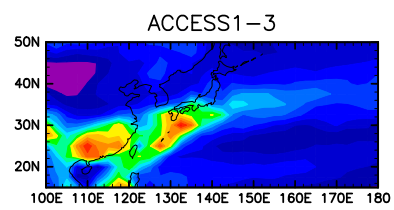

CCSM4

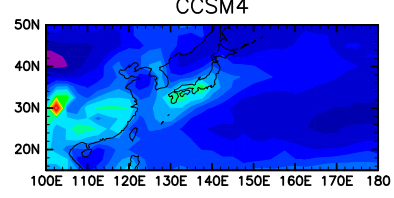

CMCC-CMS

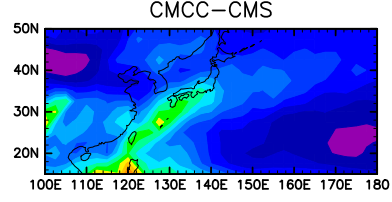

GFDL-CM3

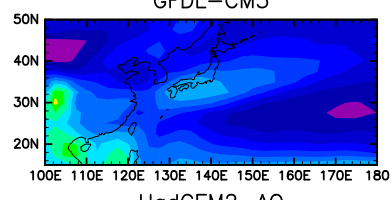

HadGEM2-AO

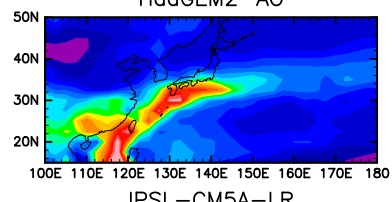

IPSL-CM5A-LR
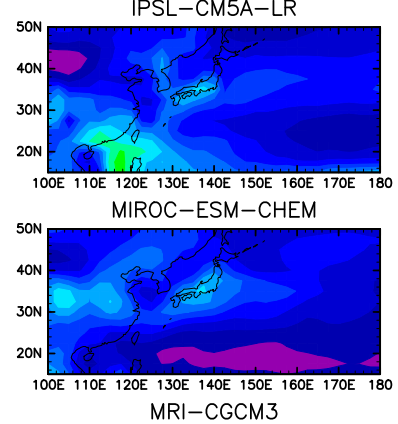

MRI-CGCM3

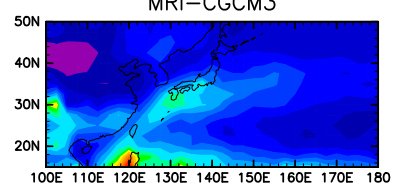

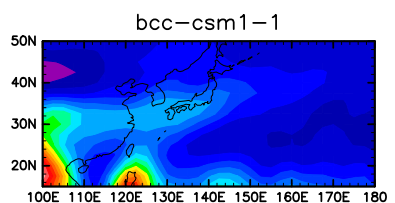

CESM 1-BGC

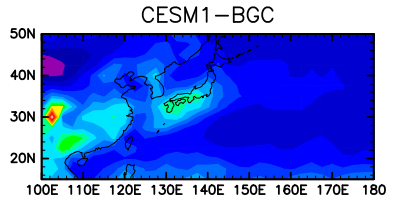

CNRM-CM5

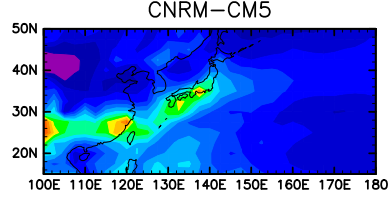

GISS-E2-H

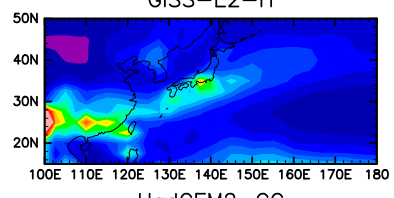

HadGEM2-CC

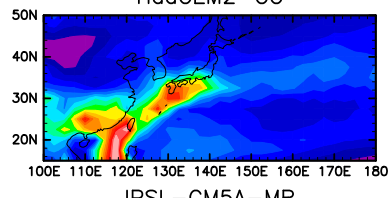

IPSL-CM5A-MR
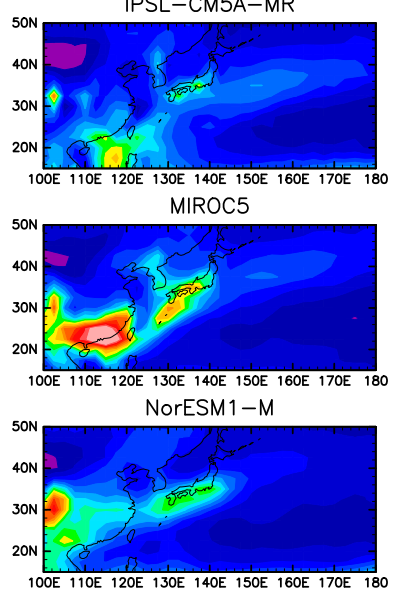

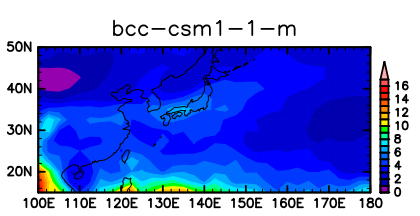

CESM1-CAM5

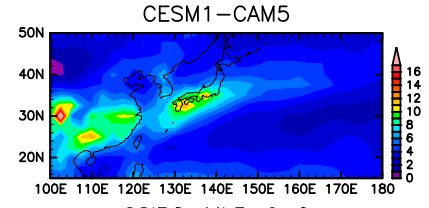

CSIRO-Mk3-6-0

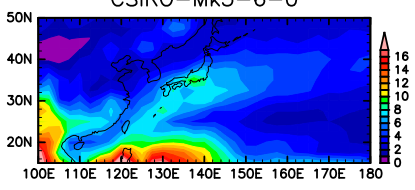

GISS-E2-H-CC

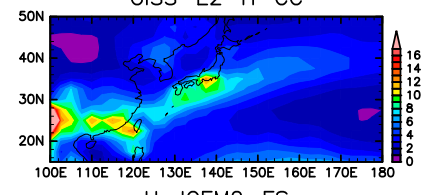

HadGEM2-ES

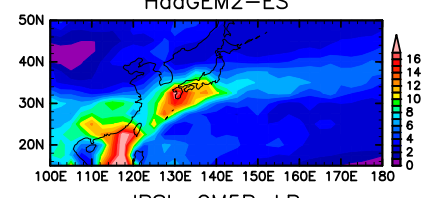

IPSL-CM5B-LR
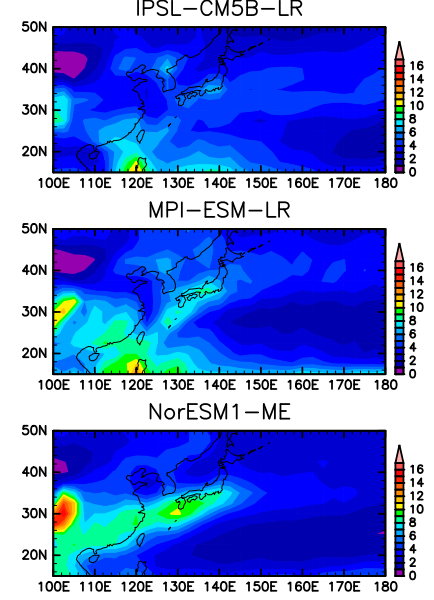

FIG. 2. Long-term-mean precipitation over June and July during 1979-99 for each model of the historical runs ( $\left.\mathrm{mm} \mathrm{day}^{-1}\right)$.

CMCC-CM, CMCC-CMS, CNRM-CM5, CSIRO-Mk3.6.0, FIO-ESM, GFDL-CM3, GISS-E2-H, GISS-E2-H-CC, GISSE2-R-CC, HadGEM2-AO, HadGEM2-CC, HadGEM2-ES, INMCM4, IPSL-CM5A-LR, IPSL-CM5A-MR, IPSLCM5B-LR, MIROC-ESM, MIROC-ESM-CHEM, MIROC5, MPI-ESM-LR, MPI-ESM-MR, MRI-CGCM3, NorESM1-M, and NorESM1-ME]. See Kirtman et al. (2014) and Collins et al. (2014) for a summary of the models (expansions of acronyms are available online at http://www.ametsoc.org/PubsAcronymList). For reference, long-term-mean precipitation values over June and July of 1979-99 for each model of the historical runs are shown in Fig. 2.

Daily mean data are also available for some of the models, and we used 16 models for historical runs, as shown in Fig. 3. Daily mean data from RCP4.5 runs are also used. All the CMIP5 data are used after horizontally interpolating onto a $2.5^{\circ} \times 2.5^{\circ}$ grid by using the bilinear interpolation. The available pressure levels up to $100 \mathrm{hPa}$ are $1000,925,850,700,600,500,400,300,250$, 200,150 , and $100 \mathrm{hPa}$ for monthly data and 1000,850 , $700,500,250$, and $100 \mathrm{hPa}$ for daily data. 

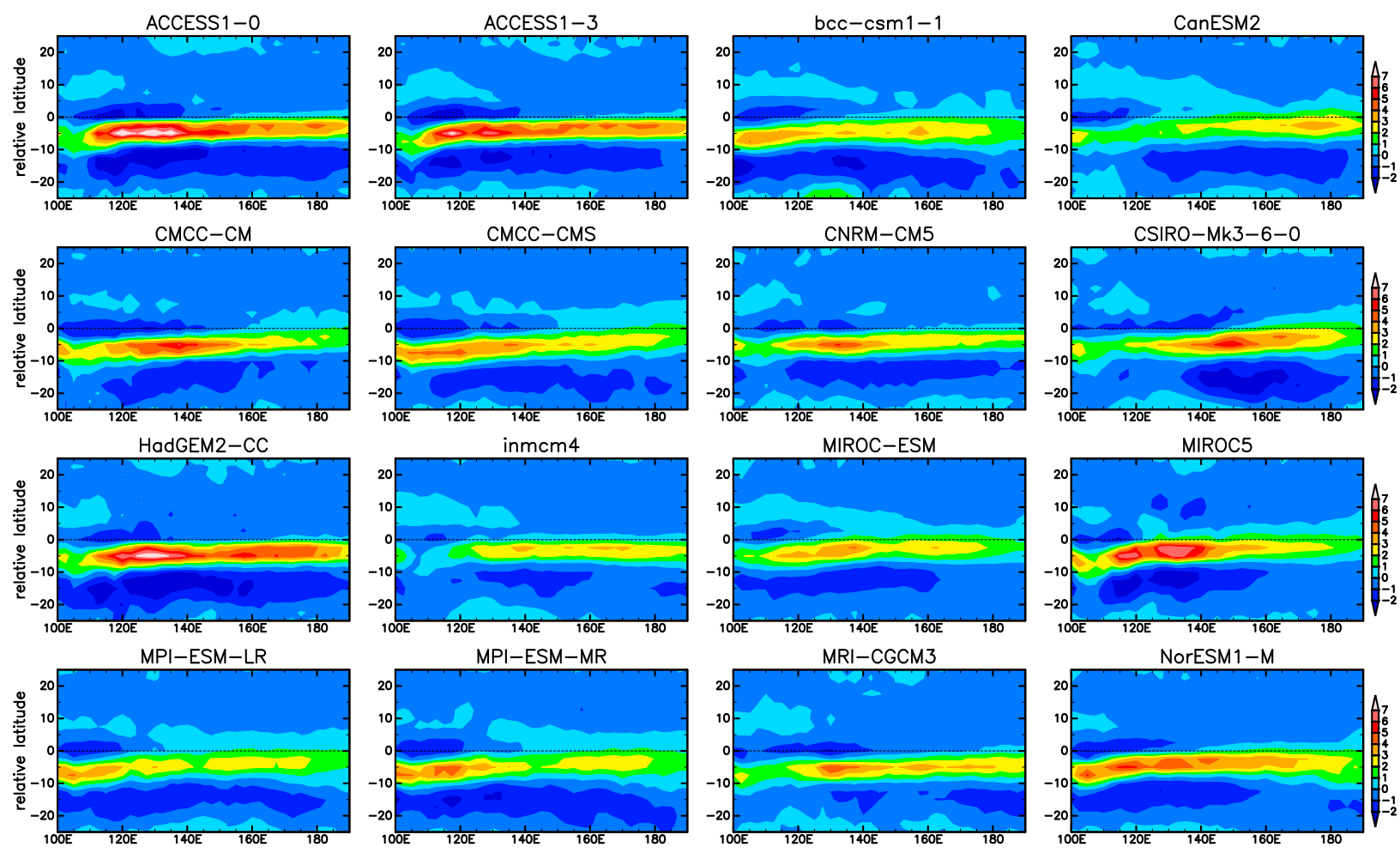

FIG. 3. Composite mean of daily precipitation anomaly $\left(\mathrm{mm} \mathrm{day}^{-1}\right)$ by shifting it meridionally with respect to the jet axis. Here, the precipitation anomaly is defined as the deviation from the monthly (June or July) long-term mean precipitation for each model of historical runs during 1979-99; the jet axis is defined as the meridional grid point having the southernmost local maximum of daily mean zonal wind at $250 \mathrm{hPa}$ between $25^{\circ}$ and $50^{\circ} \mathrm{N}$ above the threshold $U_{T}=15 \mathrm{~m} \mathrm{~s}^{-1}$. The results are shown as functions of longitude and relative latitude with respect to the jet axis.

For comparison, atmospheric reanalysis data from the Japanese 55-year Reanalysis (JRA-55) by the Japan Meteorological Agency (Kobayashi et al. 2015) and the version 7 Tropical Rainfall Measuring Mission (TRMM) Multisatellite Precipitation Analysis (TMPA) 3B42 product (Huffman et al. 2007) are used. The JRA-55 data have a resolution of $1.25^{\circ} \times 1.25^{\circ}$. The TMPA $3 \mathrm{~B} 42$ data originally had a resolution of $0.25^{\circ} \times 0.25^{\circ}$, but they were binned onto a $1.25^{\circ} \times 1.25^{\circ}$ grid in this study. For both sets of data, daily mean values in June and July are used over the years 2001-15. Also, the 1981-2010 climatological precipitation from the CPC Merged Analysis of Precipitation (CMAP) standard data are used.

In section 3, composite analysis with respect to the subtropical jet axis is conducted. The jet axis in the composite analysis is defined for each longitude as the meridional grid point having the southernmost local maximum of zonal wind at $250 \mathrm{hPa}$ between $25^{\circ}$ and $50^{\circ} \mathrm{N}$ above a threshold (in many cases, $15 \mathrm{~m} \mathrm{~s}^{-1}$ ). Here, the jet axis is defined for each day (month) when daily mean (monthly mean) data are composited. Similarly, it is defined from long-term-mean zonal wind for each model when long-term-mean data are composited across models. The target quantity is averaged over time as a function of longitude and relative latitude with respect to the jet axis; more specifically, it is done, first, by shifting the latitudinal grid with respect to the grid point where zonal wind is maximized between $25^{\circ}$ and $50^{\circ} \mathrm{N}$ for each longitude and time (here, no interpolation was made) and, second, by averaging over time. The entire daily or monthly data are used for time averaging, since we set the threshold values low enough (the actual values are found in the next section). This analysis is similar to the one conducted by Yokoyama et al. (2017). It was confirmed with the CMIP5 data that similar results are obtained if the composite is made with respect to the isentropic $(350 \mathrm{~K})$ and constant potential vorticity (2 PVU) contours as in H14 and HH17. The reason we rather used the jet axis is as follows: CMIP5 daily data are vertically sparse, so the vertical derivative needed to derive potential vorticity must depend on very sparse data; also, and more importantly, it is simple to use the jet axis, even though its dynamical meaning is less clear than the tropopause gap and associated potential vorticity structure (see HH17).

Unlike in the above-mentioned composite analysis, the jet axis is determined at subgrid scale in the correlation and future change analyses presented in sections 4 

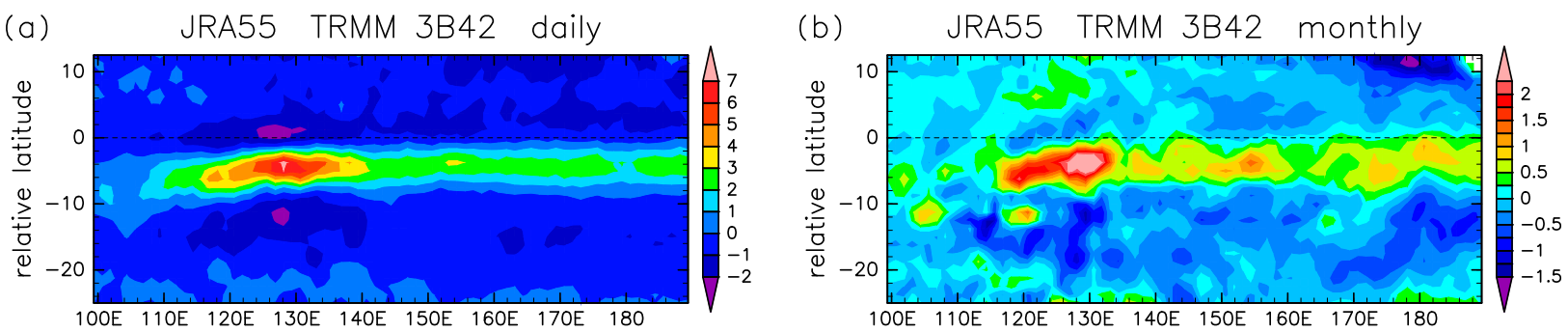

FIG. 4. (a) As in Fig. 3, but for daily observational/reanalysis data over 2001-15. The 250-hPa jet axis is defined by using JRA-55 zonal wind, and the precipitation anomaly is defined by using TRMM 3B42 data. (b) As in (a), but for monthly mean data.

and 5 . This is because the discretization by the $2.5^{\circ}$ grid is too coarse to examine small positional changes in each model, even though it may be acceptable if model ensembles are of interest. The subgrid determination was done with the parabolic interpolation using three points.

\section{Jet axis and precipitation}

We begin with presenting results from daily mean data to investigate whether the observed relationship between jet and precipitation over the northwestern Pacific is generally reproduced in CMIP5 models. Figure 3 shows the composite mean of daily precipitation anomaly from each model's climatology for historical runs with respect to the jet axis at $250 \mathrm{hPa}$. Note that the resultant values would be zero if the jet did not move meridionally at all, since in that case the composite mean would be equal to the Eulerian time mean to derive the climatology (here, for each of June and July). Therefore, positive anomalies to the south of the zero relative latitude indicate that precipitation is enhanced to the south of the UTLS jet axis, which often demarks the stratospheric and tropospheric air masses on isentropic surfaces (e.g., HH17). This precipitation enhancement exists in all models over $\sim 0^{\circ}-10^{\circ}$ relative latitude. As shown by $\mathrm{H} 14$ (see section 1 ), the special correspondence of the jet (or the tropicalextratropical tropopause break) and the precipitation anomaly is mainly driven by the former rather than the latter. The precipitation anomaly is negative farther south $\left(\sim 10^{\circ}-20^{\circ}\right.$ relative latitude). The figure's observational counterpart is shown in Fig. 4a. In some models in Fig. 3, the composite anomaly is stronger than is observed. The results of the same composite for the future based on RCP4.5 are very similar to Fig. 3 for each model (not shown). This persistency indicates that simulated synoptic features of precipitation tend to be preserved irrespective of changes in greenhouse gas concentrations.

Figure 5 shows the results of similar composite but using monthly mean data. The increase and decrease to the south of jet axis is also found here, which indicates that the monthly jet axis and latitudes of peak precipitation tend to covary. In other words, their interannual variability is positively correlated. A comparison of Figs. 3 and 5 suggests that the intermodel differences are similar between the daily and monthly composites. For example, the models in which the daily precipitation anomaly is relatively great tend to exhibit a relatively large monthly precipitation anomaly, and the longitudinal distribution tends to be similar between daily and monthly composites. We use the monthly mean data for analyses hereafter, since we can use larger model ensembles (32 models) compared to daily mean values (16 models).

Quantitatively, the composite anomaly is much stronger in daily means than in monthly means. A typical value of the enhancement to the south of jet axis is $\sim 4 \mathrm{~mm} \mathrm{day}^{-1}$ for daily means (Fig. 3 ) and $\sim 1 \mathrm{~mm}$ day $^{-1}$ for monthly means (Fig. 5). This difference indicates that the relationship between jet and precipitation is established quite fast on the synoptic time scale. Since synoptic disturbances move the jet axis meridionally, the composite anomaly based on monthly mean (Fig. 5) is blurred, so its magnitude is smaller than in Fig. 3.

The observational counterpart to Fig. 5 is shown in Fig. 4b. The composite anomaly here is noisier than in Fig. 5, partially due to spottiness of the real precipitation and perhaps also due in part to the shortness of the years covered.

Simple precipitation climatology shown in Fig. 2 indicates a wide intermodel variety in the EASM precipitation distributions. All models have precipitation belts corresponding to the baiu rainband to the east of $\sim 120^{\circ} \mathrm{E}$, although the distribution and the strength are quite different among models. On the other hand, the weak mei-yu precipitation peak over the continent at $\sim 30^{\circ} \mathrm{N}$ (see Fig. 1 for observational climatology) is not always reproduced by CGCMs. The same plots as Fig. 2 but for the RCP4.5 and RCP8.5 runs (not shown) reveal that the precipitation distribution is very similar between the present and future conditions for each model, except that it is increased because of the global warming (not shown).

Figure 6 summarizes the composite of the monthly mean anomaly as the multimodel mean (MMM) composite. The statistical significance shown in the figure 

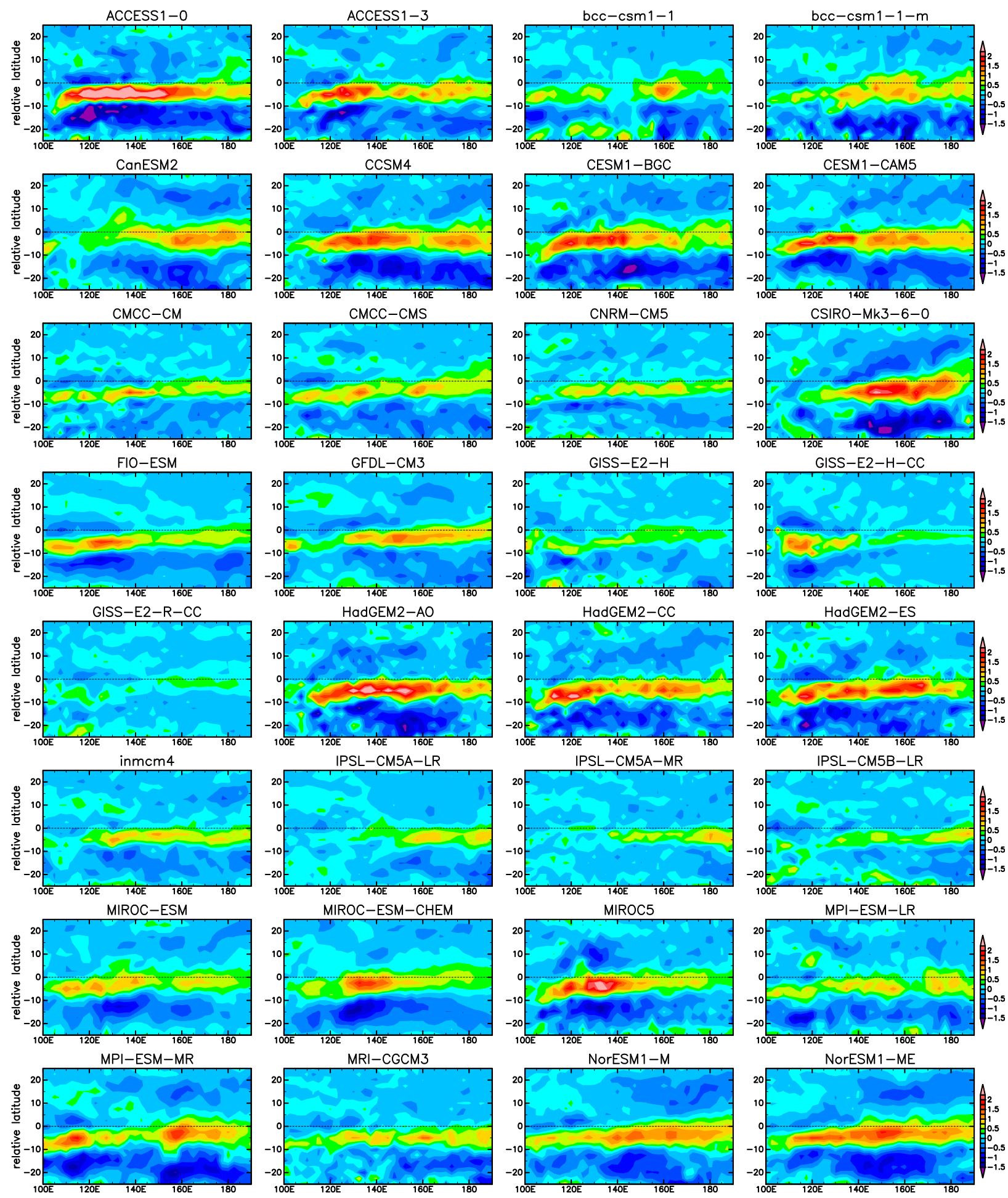

FIG. 5. As in Fig. 3, but for monthly mean precipitation anomaly $\left(\mathrm{mm} \mathrm{day}^{-1}\right)$ for each model relocated with respect to the jet axis derived from monthly mean 250-hPa zonal wind when it is positive $\left(U_{T}=0 \mathrm{~m} \mathrm{~s}^{-1}\right)$. 
(a)

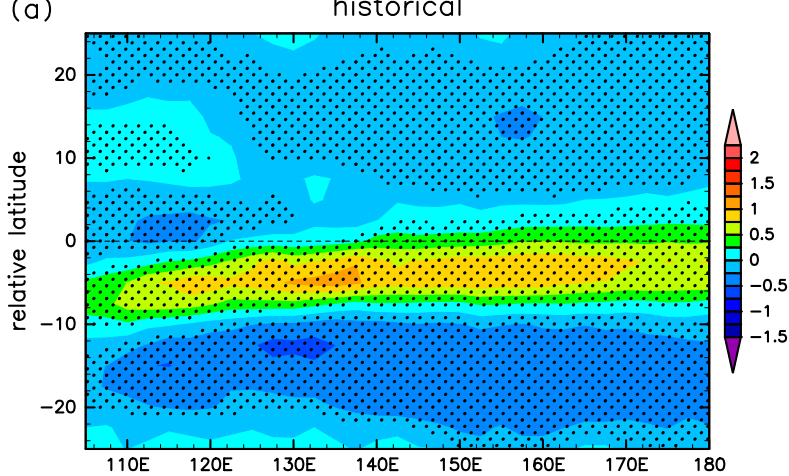

(b)

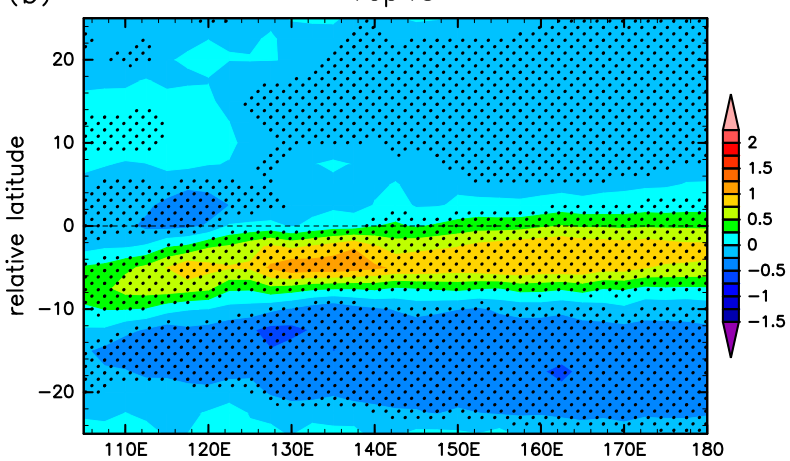

(c)

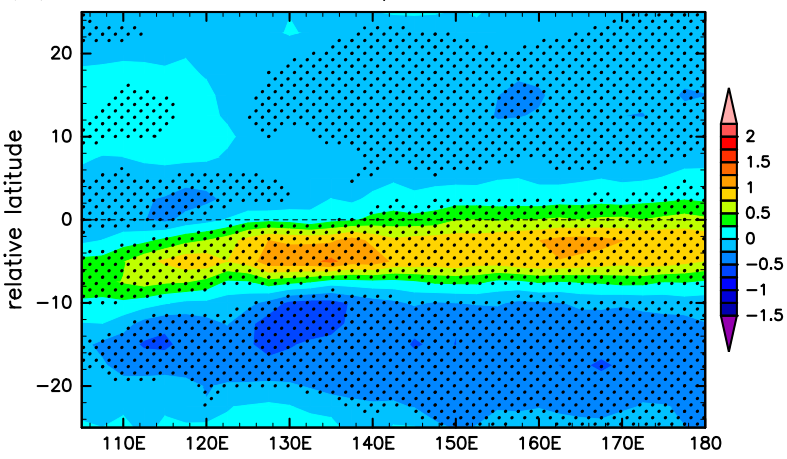

FIG. 6. (a) MMM jet-relative composite of monthly mean precipitation anomaly obtained by averaging the results shown in Fig. 5 over the 32 models $\left(\mathrm{mm} \mathrm{day}^{-1}\right)$. Stippling is made where the significance against zero is greater than $95 \%$ using the Student's $t$ test. The number of ensemble members used here is 1344 , derived from the 32 models for each of June and July in 21 years ( 32 $\times 2 \times 21$ ). (b) As in (a), but for the RCP4.5 runs. (c) As in (a), but for the RCP8.5 runs.

indicates the robustness of the argument presented above. It also shows the similarity among the historical, RCP4.5, and RCP8.5 runs except for the increase of precipitation by warming. If the same figure is produced with respect to the jet axis at lower pressure levels (such as 500 and $850 \mathrm{hPa}$ ), similar results are obtained, but the anomalies are generally shifted to the north, reflecting
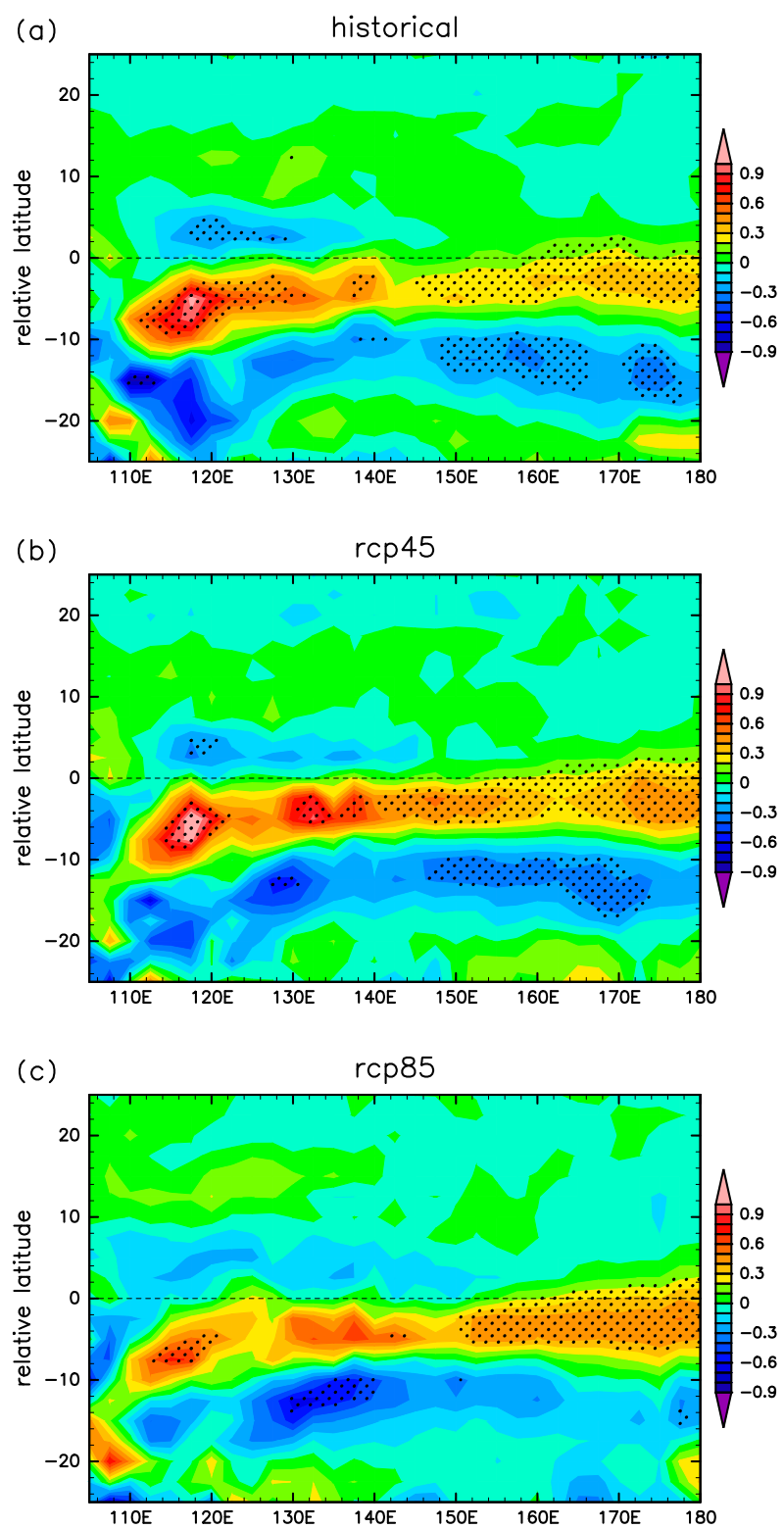

FIG. 7. As in Fig. 6, but for the composite based on the intermodel anomaly of the long-term (21 yr) mean precipitation (the deviation of model climatology from the MMM monthly climatology) shifted meridionally with respect to the climatological jet axis for each model. The number of ensemble members used here is 64 (32 models $\times 2$ months).

the fact that jet in the troposphere is meridionally tilted northward with height.

So far, we have shown that the relationship of the UTLS jet axis and the precipitation (i.e., that the precipitation maximum stays to the south of the jet) holds for both daily mean and monthly mean data. Here, we examine if this relationship also holds for longer-term means. Figure 7 shows the same composites but based 


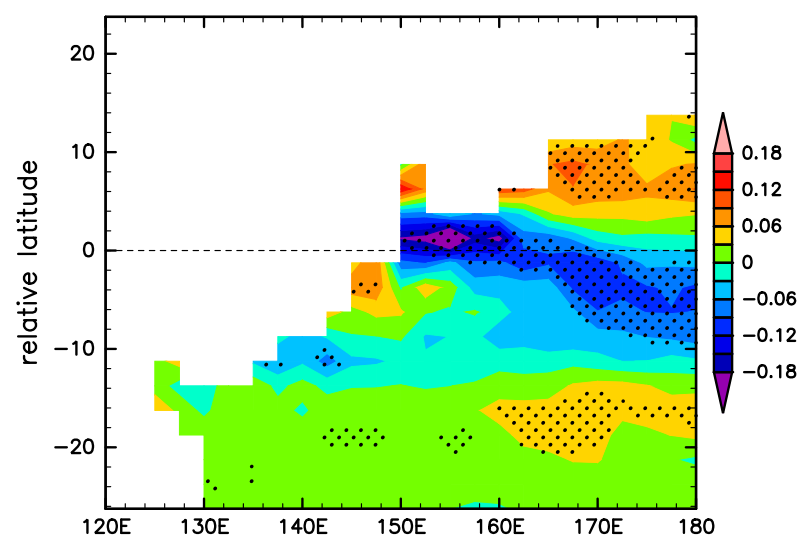

FIG. 8. As in Fig. 7a, but for the composite of meridional SST gradient anomaly $\left[\mathrm{K}\left(1^{\circ}\right)^{-1}\right]$. Here, the gradient is derived from the central differentiation over two adjacent grid points. The computation is made only where the SST is defined in all the models.

on climatological (21 yr) averages of June and July for each model. Although the significance is not necessarily high, the result suggests that the above-mentioned jetprecipitation covariation holds even despite the differences among the models. That is, if the simulated jet axis is at relatively at low (high) latitudes, the precipitation belt tends to be situated at relatively low (high) latitudes. The negative anomaly to its south is also present on this climatological time scale.

Simulated climatological jet position is correlated with the SST front associated with the KuroshioOyashio Extension. Figure 8 is the same composite as in Fig. 7a but for the long-term-mean meridional SST gradient anomaly. Figure 8 indicates that the jet axis tends to be situated around the anomalous SST gradient to the west of $160^{\circ} \mathrm{E}$. Here, we do not pin down the causality between jet and SST gradient; on the one hand, the SST gradient can affect zonal wind through the thermal wind balance and the change in baroclinicity, but on the other hand the jet (or atmospheric pressure configuration) can affect SST. The same composite results for RCP4.5 and RCP8.5 exhibit similar features as in Fig. 8, but the composite anomaly is slightly weaker (not shown).

The results presented in this section indicate that the jet-precipitation relation shown in earlier studies holds robustly over a wide range of time scales in the CGCM simulations (daily means, monthly means, and climatological means) in the CGCM simulations. The relation holds in both present and future climates. The EASM precipitation distribution in each model does not change much except for the overall increase. However, there do exist future changes in the meridional distribution, which are investigated in the next section.

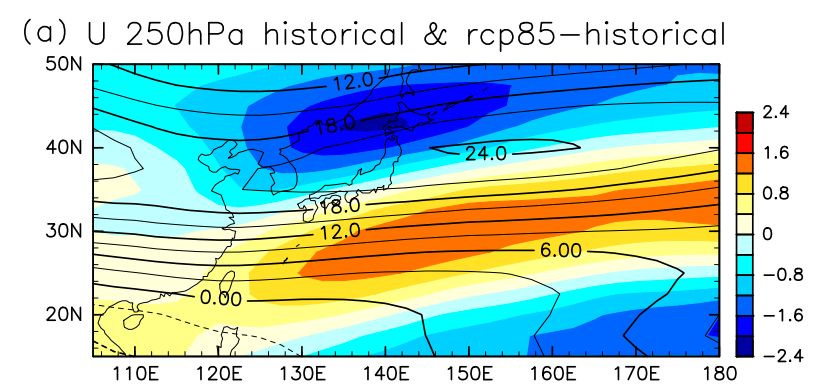

(b) Precip historical \& rcp85-historical

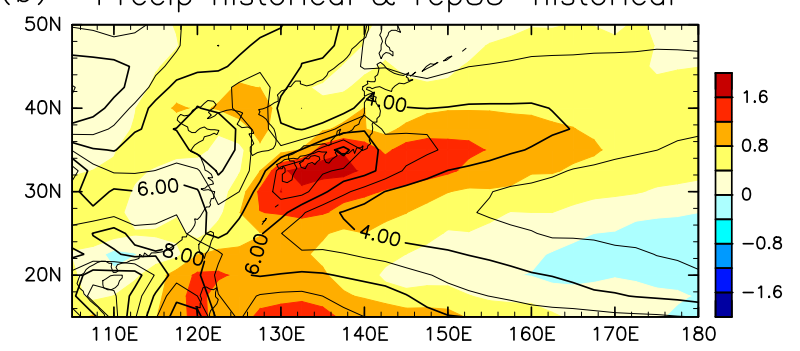

FIG. 9. (a) Historical MMM June-July climatology (1979-99) of zonal wind at $250 \mathrm{hPa}$ (contours; $\mathrm{m} \mathrm{s}^{-1}$ ) and the simulated MMM future change as the 2079-99 RCP8.5 climatology minus the historical climatology. (b) As in (a), but for precipitation $\left(\mathrm{mm} \mathrm{day}^{-1}\right)$.

\section{Future change}

Since the overall increase of EASM precipitation associated with the increase of greenhouse gases has been well established, we focus here on the change in spatial distributions, particularly the meridional shift of jet and precipitation. Simulated MMM future change in 250hPa June-July zonal wind from the late twentieth to late twenty-first centuries is shown in Fig. 9a, based on RCP8.5. Zonal wind over $120^{\circ} \mathrm{E}-180^{\circ}$ (over the northwestern Pacific) is accelerated and decelerated to the south and to the north, respectively, of the climatological jet, indicating that it is shifted southward. Also, the peak speed is decelerated. The monthly time sequence of the simulated future change (not shown) is more like a pure southward shift in June; deceleration along the jet axis as well as the southward shift occurs in July, and it is more like a pure deceleration in August. In cold seasons, the jet shift is predominantly northward. A similar seasonal march of future changes was reported for zonal wind at $850 \mathrm{hPa}$ by Grise and Polvani (2014).

Simulated future change in June-July precipitation is shown in Fig. 9b. As is well known, MMM precipitation is generally increased. Taking a close look, the increase is greater to the south than to the north of the baiu rainband to the east of $\sim 125^{\circ} \mathrm{E}$, indicating that the MMM baiu rainband is also shifted to the south. On the other hand, the MMM future change of mei-yu precipitation over China is not clear except for the overall 
TABLE 1. Mean meridional shift (positive if northward) and its standard deviation of the peak latitudes of June-July 250-hPa zonal wind $U$ and surface precipitation (Precip) over a century from historical to RCP4.5 or RCP8.5 runs. Also shown are correlation coefficients among the shifts of the two quantities. Single and double asterisks indicate that the sign of the shift is significant at the $95 \%$ and $99 \%$ confidence levels, respectively, using the Student's $t$ test. Shifts in individual models are shown in Fig. 10.

\begin{tabular}{lllcr}
\hline \hline & & Mean meridional shift $\left(^{\circ}\right)$ & Standard deviation $\left(^{\circ}\right)$ & Correlation coefficient \\
\hline RCP4.5 & $U$ & $-0.42^{*}$ & 0.78 & $0.56^{* *}$ \\
& Precip & -0.19 & 0.55 & 0.97 \\
RCP8.5 & $U$ & $-0.94^{* *}$ & 0.86 & $0.38^{*}$ \\
& Precip & $-0.41^{*}$ & 0.86 & \\
\hline
\end{tabular}

increase. This result may be because the MMM jet changes are weak over the eastern part of China (Fig. 9a). Note that, from Fig. 7, the intermodel positional association of climatological precipitation and the jet is robust over there $\left(110^{\circ}-120^{\circ} \mathrm{E}\right)$ as well as over the Pacific. However, the unclearness of the mei-yu distribution change may also because the mei-yu is not reproduced in some models and the MMM precipitation (Fig. 9b) does not reproduce the mei-yu precipitation peak in the present climate (Fig. 1), suggesting a limitation of climate models at the time of CMIP5. In what follows, therefore, we will concentrate on the change in the baiu region to the east of the Eurasian continent.

We computed the simulated future shifts of $250-\mathrm{hPa}$ jet axis and baiu precipitation peak latitudes. Their mean values and standard deviations are shown in Table 1, and the relation between the jet shift and precipitation peak latitude shift in individual models is shown in Fig. 10. Here, the peak latitudes between $25^{\circ}$ and $50^{\circ} \mathrm{N}$ are determined by applying the three-point formula described in section 2 to zonal wind and precipitation, which are averaged over $135^{\circ}-150^{\circ} \mathrm{E}$ and from June to July. Of the 32 models, two models are not used because the precipitation maximum is located at $25^{\circ} \mathrm{N}$ (at one end of the latitudinal scope), indicating that the baiu precipitation peak inside the range is faint.

As shown in Table 1, both jet axis and baiu precipitation peak slightly shift southward in future on the average; as for the RCP8.5 scenario, both shifts are statistically significant (see asterisks in Table 1). However, some models show opposite shifts, as shown in Fig. 10. The shifts of the jet axis and baiu precipitation peak latitudes are positively correlated; the more the jet is shifted southward, the more the precipitation peak tends to be shifted southward too. From the analyses in section 3 , this correlation is likely driven dynamically, and it is likely the former (the shifts of jet axis) rather than the latter (baiu precipitation peak latitudes) that dominate the correlation, as suggested by Sampe and Xie (2010), whose mechanism is reinforced by the study of HH17 in a different way (see section 1).

In section 3, it was shown that the intermodel variability of the meridional position of the climatological jet axis is correlated with the SST gradient anomaly.
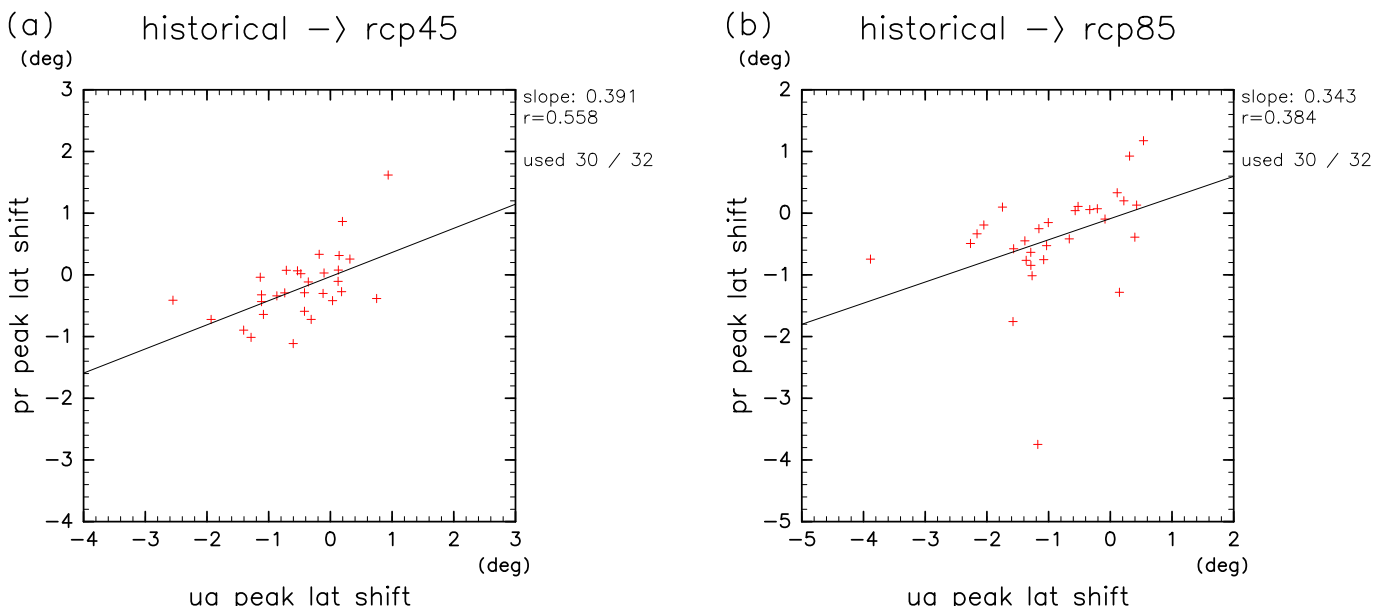

FIG. 10. Simulated future latitudinal shifts (positive if northward) of the climatological 250-hPa jet axis and the baiu precipitation peak derived from zonal wind and precipitation, respectively, averaged over $135^{\circ}-150^{\circ} \mathrm{E}$ and from June to July for each model: (a) change from historical (1979-99) to RCP4.5 (2079-99) climatology, and (b) change from historical to RCP8.5. Solid lines are regression lines. The correlation coefficients $r$ and the slopes are shown to the right of the panels. 


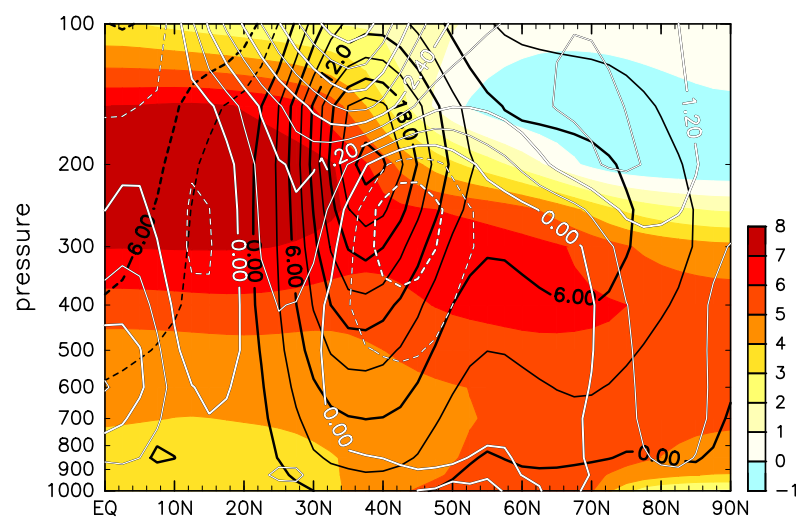

FIG. 11. MMM changes from present (historical; 1979-99) to future (RCP8.5; 2079-99) temperature (color shading; K) and zonal wind (white contours; interval: $0.6 \mathrm{~m} \mathrm{~s}^{-1}$ ), as well as the present zonal wind (black contours; interval: $3 \mathrm{~m} \mathrm{~s}^{-1}$ ). All the quantities are longitudinally averaged over $120^{\circ}-150^{\circ} \mathrm{E}$. Dashed contours show negative values.

However, we have not found significant intermodel association between the future meridional changes in the jet axis locations and those in the SST front locations (not shown). This subject is left for future studies.

Zonal wind changes are associated with temperature changes through the thermal wind relation. It can be illustrated in a MMM meridional cross section as in Fig. 11, which shows changes over a century based on RCP8.5. The zonal wind increase to the south of the jet axis is accompanied with the increase of poleward temperature gradient. This change is accompanied with the upper-tropospheric enhancement of tropical warming, a well-known feature associated with the global warming. Also, the zonal-wind decrease to the north of the jet axis is accompanied with a decrease of the poleward temperature gradient, which is associated with the temperature change in midlatitude. The figure also shows that the MMM zonal wind change is small in the lower troposphere.

To reliably simulate future changes in climatological precipitation distribution is a difficult task and the above-mentioned southward shift of baiu precipitation peak is still uncertain. In such a case, it is important to elucidate relevant processes, which helps assessment of future modeling results. The relationship between the climatological jet and precipitation elucidated in this study suggests that jet is an important component to be evaluated in the projection of the future change of the EASM.

\section{Discussion}

It has been pointed out that the Hadley circulation has been expanding due to the global warming (e.g., Seidel et al. 2008; Lucas et al. 2014). Lau and Kim (2015) revealed a robust expansion of the Hadley circulation in the MMM of 33 CMIP5 simulations in which $\mathrm{CO}_{2}$ emission is increased by $1 \% \mathrm{yr}^{-1}$. Therefore, the southward shift of the subtropical jet over the northwestern Pacific shown in this study appears to counteract the global change. Indeed, the jet shifts poleward in the Atlantic in the boreal summer [Fig. 12; a similar feature was shown by Grise and Polvani (2014) for the lower troposphere]. Observational evidences suggest that the distance between the jets in the Northern and Southern Hemispheres has increased in terms of zonal mean (Seidel et al. 2008).

Consistent with Lau and Kim (2015), the annual-mean MMM meridional mass streamfunction (computed from meridional wind averaged over entire longitudinal circles) also exhibits poleward expansion of the Hadley cells for RCP8.5 (Fig. 13a). Taking a close look, however, the expansion is smaller in the Northern Hemisphere. In the boreal summer, the northern cell is weak, and the expansion occurs only in the southern cell (Fig. 13b). Therefore, it is not surprising that the local subtropical jet in the northwestern Pacific is shifted southward.

The above argument suggests that instead it should be questioned how the Atlantic jet is shifted northward. Here, we should note that the Atlantic jet core is situated at around $45^{\circ} \mathrm{N}$, well separated from the Hadley circulation. The separation is evident in the meridional cross section shown in Fig. 14. The zonal wind increase associated with the tropical warming is also present over

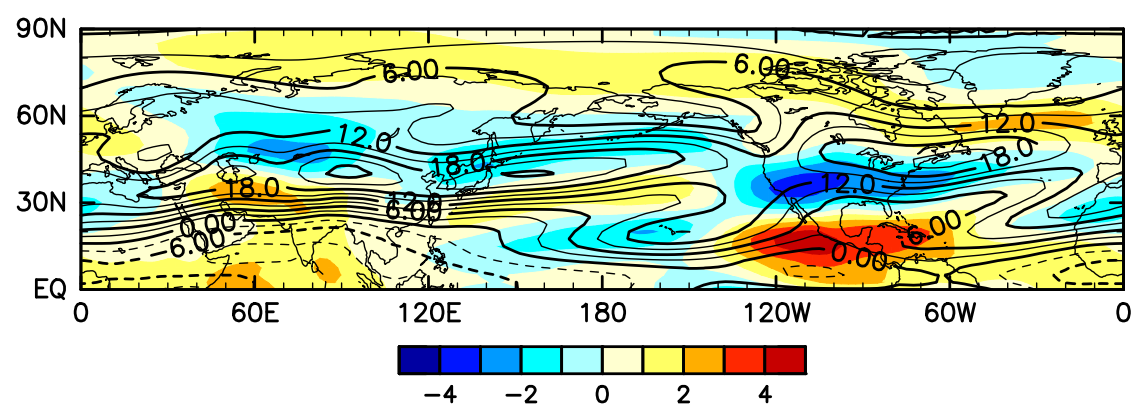

FIG. 12. The MMM present (historical) 250-hPa zonal wind $\left(\mathrm{m} \mathrm{s}^{-1}\right)$ climatology for June-July (contours) and its future change for RCP8.5 (color shading). 

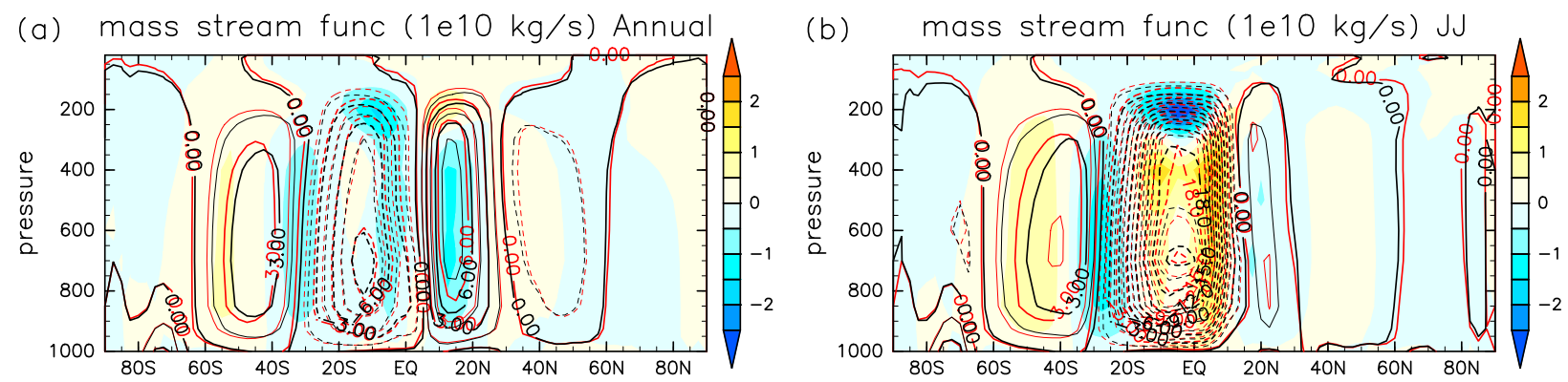

FIG. 13. (a) Meridional mass streamfunction computed from zonal-mean (over the entire longitudinal circles) annual-mean MMM meridional wind for historical (black contours) and RCP8.5 (red contours) climatology and their difference (color shading; RCP8.5 minus historical). (b) As in (a), but for the June-July period.

the Atlantic at around $20^{\circ} \mathrm{N}$, but this change is well separated from the jet core. In other words, the poleward shift of the summertime Atlantic jet core is not a manifestation of the expansion of the tropics.

Using CGCMs and AGCMs in the CMIP3 and CMIP5 databases, Sperber et al. (2013) and Song and Zhou (2014) showed that the EASM precipitation is better reproduced if the $850-\mathrm{hPa}$ wind (zonal wind or two-dimensional horizontal wind) is better reproduced, suggesting the importance of low-level flow. On the other hand, this study focused on the upper-level flow, so one can question that we should have used low-level flow. According to HH17, the upper and lower flows can interact to enhance precipitation. Since the low-level flow has a significant zonal asymmetry and it is variable among models, it can be an important factor to affect the longitudinal distribution of precipitation and its future change. However, if we draw the same figure as in Fig. 10 using zonal winds at $850 \mathrm{hPa}$ (not shown), then no significant correlation is found. This may be because of the complicated distribution of low-level wind. For this reason, as well as the consideration of the established dynamical control from upper levels, we primarily used the 250 -hPa zonal wind.

\section{Summary and conclusions}

Through extensive modeling efforts, it has been established that the ongoing global warming will increase the overall precipitation associated with the EASM, but there is not consensus as to the future change of its spatial distribution. This is partly because the simulated changes in its distribution have not been clearly identified, but perhaps it is also because detailed analyses have not been conducted to explain simulated changes.

We used outputs from CGCMs in the CMIP5 database to tackle this problem. Our strategy was to exploit the spatial and dynamical association between the summertime subtropical jet and precipitation. For this purpose, we began this study by investigating daily mean data.
It was found that the CMIP5 models reproduce the observed association between the jet and precipitation over wide time scales. Composite analyses showed that precipitation is enhanced to the south of the jet axis over a width of $10^{\circ}$. The composite anomalies based on the daily mean are several times greater than those based on the monthly mean. This result indicates that the jetprecipitation relation is established on the synoptic time scale, and it is blurred as they move but is kept over longer time scales. Furthermore, the same relation is present in the intermodel differences in long-term means, so that the variations in the baiu precipitation peak latitude and the jet axis latitude are associated with each other.

The MMM projection suggests that both the climatological jet axis and the baiu precipitation peak latitude are shifted southward by the late twenty-first century, and their intermodel variations are positively correlated with each other. On the other hand, no significant future change in the mei-yu precipitation distribution is identified, which may be because the simulated future change of jet is weak over the eastern part of China. However, the result may also because of the poor representation of mei-yu in the CMIP5 models.

One may think that the future southward jet shift counteracts the expansion of the tropics. However, we

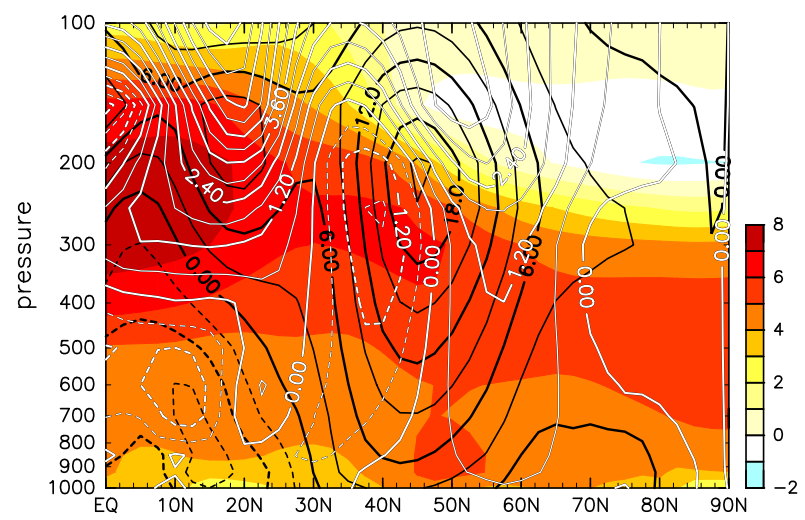

FIG. 14. As in Fig. 11, but computed from longitudinal means over $80^{\circ}-40 \mathrm{~W}^{\circ}$ (over the western Atlantic). 
showed that the MMM northern edge of the northern Hadley cell in the boreal summer does not shift poleward. It is known that the Atlantic jet in the boreal summer is shifted northward. However, the Atlantic jet is well separated from the Hadley circulation, so the effect of the tropical warming does not directly reach it in terms of the thermal wind relation. It is interesting that the MMM projection suggests the increase of climatological zonal asymmetry in the boreal summer.

The simulated west Pacific climatological jet position is correlated with the SST front associated with the Kuroshio-Oyashio Extension; it is found that the intermodel differences in the subtropical jet axis latitudes are correlated with the meridional SST gradient, whether among the present-climate results or among the future-climate results. However, we did not find a robust relationship between the future changes of the locations of the jet and those of SST fronts. This study suggests that the future change of the subtropical jet is an important aspect in investigating the future change of the baiu precipitation distribution. Further study would be needed to elucidate the role of the ocean in possible future climate change.

Acknowledgments. We thank Drs. Kenji Nakamura and Hisashi Nakamura for their valuable comments on this study. We also thank three anonymous reviewers for providing useful comments that helped us improve this paper. We acknowledge the World Climate Research Programme's Working Group on Coupled Modelling, which is responsible for CMIP, and we thank the climate modeling groups for producing and making available their model output. The CMIP5 data are provided by the U.S. Department of Energy's Program for Climate Model Diagnosis and Intercomparison (PCMDI), and interpolation onto the $2.5^{\circ}$ grid was mainly done in the S5-2 project of the Global Environment Research Fund, supported by the Ministry of the Environment, Japan. This study was supported in part by the Environment Research and Technology Development Fund (2-1503) of the Ministry of the Environment, Japan, and the Japan Society for the Promotion of Science (JSPS) Grants 16K05550 and 15H02132.

\section{REFERENCES}

Chou, C., and J. D. Neelin, 2004: Mechanisms of global warming impacts on regional tropical precipitation. J. Climate, 17, 2688-2701, https://doi.org/10.1175/1520-0442(2004)017<2688: MOGWIO $>2.0 . \mathrm{CO} ; 2$.

Collins, M., and Coauthors, 2014: Long-term climate change: Projections, commitments, and irreversibility. Climate Change 2013: The Physical Science Basis, T. F. Stocker et al., Eds., Cambridge University Press, 1029-1136.
Frankignoul, C., N. Sennechael, Y.-O. Kwon, and M. A. Alexander, 2011: Influence of the meridional shifts of the Kuroshio and the Oyashio Extensions on the atmospheric circulation. J. Climate, 24, 762-777, https://doi.org/10.1175/ 2010JCLI3731.1.

Grise, K. M., and L. M. Polvani, 2014: The response of midlatitude jets to increased $\mathrm{CO}_{2}$ : Distinguishing the roles of sea surface temperature and direct radiative forcing. Geophys. Res. Lett., 41, 6863-6871, https://doi.org/10.1002/2014GL061638.

Held, I. M., and B. J. Soden, 2006: Robust responses of the hydrological cycle to global warming. J. Climate, 19, 5686-5699, https://doi.org/10.1175/JCLI3990.1.

Horinouchi, T., 2014: Influence of upper tropospheric disturbances on the synoptic variability of precipitation and moisture transport over summertime East Asia and the northwestern Pacific. J. Meteor. Soc. Japan, 92, 519-541, https://doi.org/ 10.2151/jmsj.2014-602.

_ , and A. Hayashi, 2017: Meandering subtropical jet and precipitation over summertime East Asia and the northwestern Pacific. J. Atmos. Sci., 74, 1233-1247, https://doi.org/10.1175/JAS-D-16-0252.1.

Huffman, G. J., and Coauthors, 2007: The TRMM Multisatellite Precipitation Analysis (TMPA): Quasi-global, multiyear, combined-sensor precipitation estimates at fine scales. J. Hydrometeor., 8, 38-55, https://doi.org/10.1175/JHM560.1.

Inatsu, M., H. Mukougawa, and S. P. Xie, 2002: Stationary eddy response to surface boundary forcing: Idealized GCM experiments. J. Atmos. Sci., 59, 1898-1915, https://doi.org/10.1175/ 1520-0469(2002)059<1898:SERTSB >2.0.CO;2.

Kimoto, M., 2005: Simulated change of the East Asian circulation under global warming scenario. Geophys. Res. Lett., 32, L16701, https://doi.org/10.1029/2005GL023383.

Kirtman, B., and Coauthors, 2014: Near-term climate change: Projections and predictability. Climate Change 2013: The Physical Science Basis, T. F. Stocker et al., Eds., Cambridge University Press, 952-1028.

Kitoh, A., and T. Uchiyama, 2006: Changes in onset and withdrawal of the East Asian summer rainy season by multi-model global warming experiments. J. Meteor. Soc. Japan, 84, 247258, https://doi.org/10.2151/jmsj.84.247.

Kobayashi, S., and Coauthors, 2015: The JRA-55 Reanalysis: General specifications and basic characteristics. J. Meteor. Soc. Japan, 93, 5-48, https://doi.org/10.2151/jmsj.2015-001.

Kodama, Y., 1992: Large-scale common features of subtropical precipitation zones (the Baiu frontal zone, the SPCZ, and the SACZ). Part I: Characteristics of subtropical frontal zones. J. Meteor. Soc. Japan, 70, 813-836, https://doi.org/10.2151/ jmsj1965.70.4_813.

_ 1993: Large-scale common features of sub-tropical convergence zones (the Baiu frontal zone, the SPCZ, and the SACZ). Part II: Conditions of the circulations for generating the STCZs. J. Meteor. Soc. Japan, 71, 581-610, https://doi.org/ 10.2151/jmsj1965.71.5_581.

Kripalani, R. H., J. H. Oh, and H. S. Chaudhari, 2007: Response of the East Asian summer monsoon to doubled atmospheric $\mathrm{CO}_{2}$ : Coupled climate model simulations and projections under IPCC AR4. Theor. Appl. Climatol., 87, 1-28, https:// doi.org/10.1007/s00704-006-0238-4.

Kusunoki, S., and O. Arakawa, 2012: Change in the precipitation intensity of the East Asian summer monsoon projected by CMIP3 models. Climate Dyn., 38, 2055-2072, https://doi.org/ 10.1007/s00382-011-1234-7.

Lau, W. K., and K.-M. Kim, 2015: Robust Hadley circulation changes and increasing global dryness due to $\mathrm{CO}_{2}$ warming 
from CMIP5 model projections. Proc. Natl. Acad. Sci. USA, 112, 3630-3635, https://doi.org/10.1073/pnas.1418682112.

Li, H. M., L. Feng, and T. J. Zhou, 2011: Multi-model projection of July-August climate extreme changes over China under $\mathrm{CO}_{2}$ doubling. Part I: Precipitation. Adv. Atmos. Sci., 28, 433-447, https://doi.org/10.1007/s00376-010-0013-4.

Li, J., Z. Wu, Z. Jiang, and J. He, 2010: Can global warming strengthen the East Asian summer monsoon? J. Climate, 23, 6696-6705, https://doi.org/10.1175/2010JCLI3434.1.

Lucas, C., B. Timbal, and H. Nguyen, 2014: The expanding tropics: A critical assessment of the observational and modeling studies. Wiley Interdiscip. Rev.: Climate Change, 5, 89-112, https://doi.org/10.1002/wcc.251.

Matsumura, S., and T. Horinouchi, 2016: Pacific Ocean decadal forcing of long-term changes in the western Pacific subtropical high. Sci. Rep., 6, 37765, https://doi.org/10.1038/srep37765.

,--1, S. Sugimoto, and T. Sato, 2016: Response of the baiu rainband to northwest Pacific SST anomalies and its impact on atmospheric circulation. J. Climate, 29, 3075-3093, https:// doi.org/10.1175/JCLI-D-15-0691.1.

Min, S.-K., E.-H. Park, and W.-T. Kwon, 2004: Future projections of East Asian climate change from multi-AOGCM ensembles of IPCC SRES scenario simulations. J. Meteor. Soc. Japan, $\mathbf{8 2}$ 1187-1211, https://doi.org/10.2151/jmsj.2004.1187.

Nakamura, M., and T. Miyama, 2014: Impacts of the Oyashio temperature front on the regional climate. J. Climate, 27, 7861-7873, https://doi.org/10.1175/JCLI-D-13-00609.1.

Sampe, T., and S.-P. Xie, 2010: Large-scale dynamics of the meiyubaiu rainband: Environmental forcing by the westerly jet. J. Climate, 23, 113-134, https://doi.org/10.1175/2009JCLI3128.1.

Seidel, D. J., Q. Fu, W. J. Randel, and T. J. Reichler, 2008: Widening of the tropical belt in a changing climate. Nat. Geosci., 1, 21-24, https://doi.org/10.1038/ngeo.2007.38.
Seo, K.-H., J. Ok, J.-H. Son, and D.-H. Cha, 2013: Assessing future changes in the East Asian summer monsoon using CMIP5 coupled models. J. Climate, 26, 7662-7675, https://doi.org/ 10.1175/JCLI-D-12-00694.1.

Shaw, T. A., and A. Voigt, 2015: Tug of war on summertime circulation between radiative forcing and sea surface warming. Nat. Geosci., 8, 560-566, https://doi.org/10.1038/ ngeo2449.

Song, F., and T. Zhou, 2014: Interannual variability of East Asian summer monsoon simulated by CMIP3 and CMIP5 AGCMs: Skill dependence on Indian Ocean-western Pacific anticyclone teleconnection. J. Climate, 27, 1679-1697, https://doi.org/ 10.1175/JCLI-D-13-00248.1.

Sperber, K. R., H. Annamalai, I.-S. Kang, A. Kitoh, A. Moise, A. Turner, B. Wang, and T. Zhou, 2013: The Asian summer monsoon: An intercomparison of CMIP5 vs. CMIP3 simulations of the late 20th century. Climate Dyn., 41, 2711-2744, https://doi.org/10.1007/s00382-012-1607-6.

Taylor, K. E., R. J. Stouffer, and G. A. Meehl, 2012: An overview of CMIP5 and the experiment design. Bull. Amer. Meteor. Soc., 93, 485-498, https://doi.org/10.1175/BAMS-D-11-00094.1.

Yokoyama, C., Y. N. Takayabu, and S. Kanada, 2014: A contrast in precipitation characteristics across the Baiu front near Japan: Part I. TRMM PR observation. J. Climate, 27, 5872-5890, https://doi.org/10.1175/JCLI-D-13-00350.1.

,-- , and T. Horinouchi, 2017: Precipitation characteristics over East Asia in early summer: Effects of the subtropical jet and lower-tropospheric convective instability. J. Climate, 30, 8127-8147, https://doi.org/10.1175/JCLI-D-16-0724.1.

Yun, K.-S., S.-H. Shin, K.-J. Ha, A. Kitoh, and S. Kusunoki, 2008: East Asian precipitation change in the global warming climate simulated by a $20-\mathrm{km}$ mesh AGCM. Asia-Pac. J. Atmos. Sci., 44, 233-247. 